\title{
APPLICABILITY OF SELECTED GROUPS OF ROUGHNESS PARAMETERS FOR DESCRIPTION OF SURFACE LAYER OF FLAT-TOP “PLATEAU” STRUCTURES
}

\author{
Maciej Kowalski', Magdalena Wiśniewska' ${ }^{1}$, Paweł Karolczak' ${ }^{1}$, Dana Stancekova² \\ 1 Wrocław University of Science and Technology, Faculty of Mechanical Engineering, Łukasiewicza 5, 50-370 \\ Wrocław, Poland, e-mail: pawel.karolczak@pwr.edu.pl; m.wisniewska@pwr.edu.pl; maciej.kowalski@pwr.edu.pl \\ 2 University of Žilina, Faculty of Mechanical Engineering, Univerzitna 1, 010 26, Žilina, Slovakia, e-mail: dana. \\ stancekova@fstroj.uniza.sk
}

Received: 2016.08 .30

Accepted: 2016.10 .18

Published: 2016.12.01

\begin{abstract}
The aim of this study is to determine the usefulness of selected 2D roughness parameters for detecting changes of geometric features and the rate the quality of the surface generated in the process of honing combustion engines sleeves. The paper presents the importance of mathematical modeling of virtual surface topography with different participation of determined and random factor. The possibilities of modeling the flat-top "plateau" surface roughness characteristic for honed surface was showed. Suitability of application of the roughness parameter for description of the selected variable characteristics of roughness profiles were determined using the correlation coefficient and the additional evaluation index designated as $t$. Indicator $t$ was used for comparing the percentage change of the tested value of modeled profile characteristics with changes selected for evaluation of the roughness parameters $2 \mathrm{D}$.
\end{abstract}

Keywords: roughness parameters, flat-top "plateau" surface, honing.

\section{INTRODUCTION}

Roughness is the natural state of any surface. Necessity for measurement of the inequality appeared when production requirements started growing, and evaluation with senses - visual or tactile stopped being appropriate. It was showed that $90 \%$ of all manufacturing defects have, in practice, their sources in surface from mechanical damage such as fatigue cracks, cracks due to stress induced by corrosion, abrasive - corrosion wear, excessive abrasive wear, corrosion, erosion, etc.

The model of the object shown in the technical drawings of machine parts assums that each surface of the object is perfectly smooth, it consists of ideal geometric surfaces and is clean. However, it is impossible to obtain such a surface, since individual machining processes leave characteristic traces on the surface $[1,2]$.
Nowadays components are manufactured for specific applications. Any deviations from the ideal geometric surface have an influence on the functional behavior of the object, i.e. characteristics such as abrasion resistance, sliding and lubricant properties, fatigue strength. A perfect example of geometrical functional structure is the surface after honing which is characterized by a net of intersecting grooves. It is used in the engine cylinder sleeves. Too shallow cracks formed on the surface of the cylinder in the process of honing don't provide proper lubrication during engines work. Too smooth surface can result in premature wear of cylinder liners and piston rings. The actual surface roughness can be described by multiple parameters. Their selection in order to best describe of geometric changes occure on the surface as a result of manufacturing processes is often a problem. To save the costs and time of real surface research mathematical modeling of surface geometry can be used. 
The use of mathematical modeling simplifies and accelerates, while expanding, analytical capabilities $[1,2]$. In this paper an attempt to determine the suitability of the use of selected groups of roughness parameters for detecting changes of geometric features and evaluating the quality of performance of the engines cylinder liners was made.

\section{HONING}

Honing is the method of treatment, mainly holes or cylindrical surfaces, with the use of the abrasive honing stones mounted on the outer or inner surface of the head. As a result of a combination of stroke and rotation movement and the pressure of tool to the surface removing material is taking place, and on the surface process generated structure with cross-hatch pattern. Regular crossing scratches have a significant positive impact on the sliding piston cooperate with the sleeve, eg. in the combustion engine. Such directional signs arise as a result of the submission of the rotational movement of the head with honing stone, with axial reciprocating movement. Significant honing effects include the ability to obtain the structure of "plateau", which is characterized by a grid of deep grooves on the smooth background. This structure provides good tribological conditions, which increase the durability of cooperating teams. Such a structure is obtained using in pretreatment coarse grained stone and for finishing fine [3, 4]. Initially, it was recommended to receive the surface of the cylinder characterized by high smoothness. Their small wear during break was stated. Advances in engine design led to the occurrence of seizing the smooth surface of the cylinder. It was considered that the resistance of the cylinder liner to seizure without additional surface treatment is greater with greater roughness height. However, a significant increase in surface roughness is also unfavorable: it calls for an increase in oil consumption and an increase wear of chromium-plated piston rings.

Smooth surface of the cylinder ensures their low wear during break-in, rough causes little tendency to blur. In contrast, a smaller honing angle reduces oil consumption (reduce emissions of toxic components), what is an aim, especially in engines with a spark self-ignition. Reduction of honing angle also reduces the thickness of the oil film, leading to energy loss and wear increase. Due to the opposite effect on the functional properties of high and low roughness height it became apparent search surfaces connecting sliding properties of smooth surfaces with high storage capacity of oil through the porous surfaces. This is how the structure of the cylinder surface are reached after two machining treatments ("plateau" surfaces) $[3,4,5]$.

The "plateau" structure combines the good sliding properties of the smooth surface with good lubrication, which provide deep scratches, being a kind of "pockets of oil" [3, 4, 5]. Relatively low fuel consumption and engine oil contribute to the protection of the environment. Therefore, it aims to optimize the geometric structure of the surface of the cylinder liner.

Quality criteria for the cylinder surface are as follows:

- the corresponding value of the surface roughness parameters,

- the corresponding value of the angle of intersection Figure 1a,

- regularly in both directions features honing,

- the surface without distortion remaining after its boring and without rolling of net of grooves,

- outer layer not separated from the base material $[5,6]$

The value of the angle of intersecting grooves should be $20^{\circ}-40^{\circ}$ measured from the horizontal reference line. The angle of intersecting grooves from the outside the specified range does not provide adequate lubrication of the cylinder liner and piston rings, which may result in their premature wear. (Fig. 1a). Moreover, scratches formed on the surface of the honed cylinder should be done symmetrically in both directions. Too broad and deep scratches or prevailing in only one direction can cause the growth of oil consumption (Fig. 1b) [5, 6].

Wave and shape errors of the cylinder are harmful to work of the piston - ring - cylinder system and we should seek to minimize them. When the height of waviness is of the same order or greater than roughness, it affects on the break-in period and the engine oil consumption. The topography of the cylinder surface has a significant influence on the performance characteristics of engines, especially in the initial period of operation (wear during break-in, oil consumption, the running time, the operating parameters of the engine). 

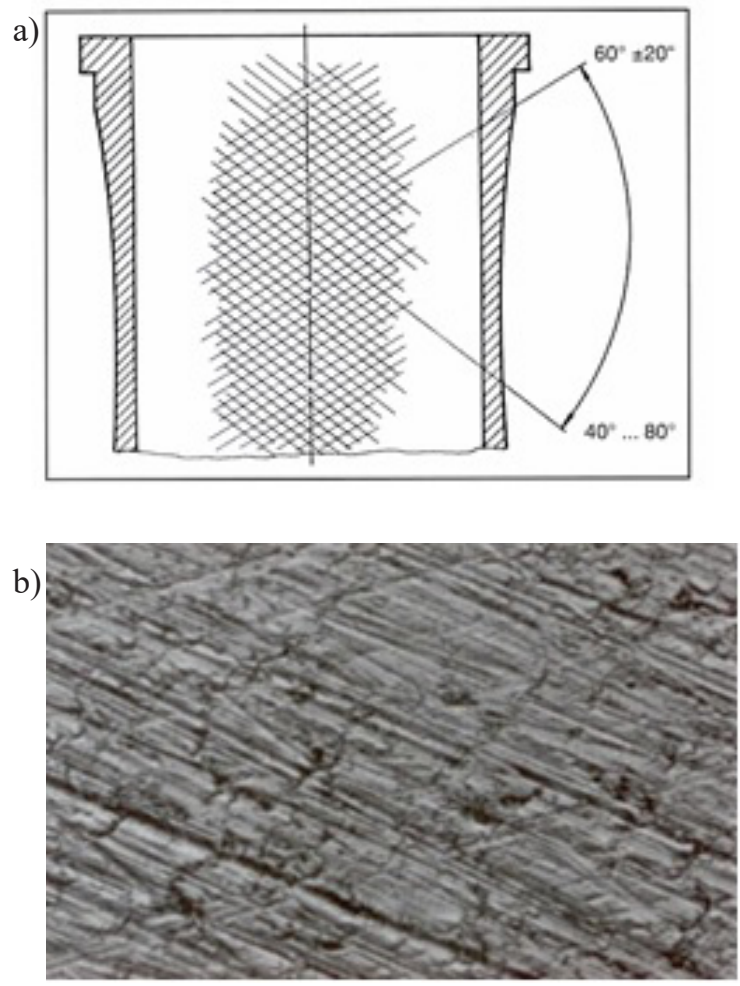

Fig. 1. "Plateau" structure: a) the angle of intersection of cracks, b) unidirectional grid pattern [7]

\section{SOFTWARE FOR SURFACE MODELING}

For surface modeling a computer program Modeling_skr, which works in the MATLAB environment was used. This program was developed at the Department of Machine Tools and Mechanical Technology of Wroclaw University of Science and Technology. The program has been designed so that it was possible to simulate the interaction of many factors affecting the constitution of technological surface layer occurring in different material removal processes and chipless machining processes. The program allows surface modeling by two methods:

- by mapping in shaped surface machining marks in a continuous basis figures or geometric solids, so called as elementary shapes, which may be ellipse, ellipsoid, torus, pyramids, cones, or other optional components designed virtually or scanned, on the shape of the elementary can be superimposed, it can be enter the random noise of its size, height and position, with this method it can be simulate the formation of the surface obtained, eg. by means of turning, milling, grinding, honing;

- by discrete "inprinting" in material elementary shapes in the form of figures or bodies de- scribed above in a regular or random way, with the possibility of distortion of the position or size of elementary lumps with this method it can be simulate the formation of the surface obtained eg. by erosion treatments, sand blasting, shot peening, burnishing.

The software allows for modeling of roughness structures both 2D (single profiles) and 3D (surface fragments). This study describes only 2D modeling.

Modeled surfaces can be repeatedly submitted with each other using mathematical functions: addition, subtraction, product, inversion, and the choice of their maximum and minimum values. This allows you to model and observe the changes in the geometry of the surface layer with overlapping of successive machining operations.

An additional option enrichment developed program is the ability to rotate modeled surface at any angle as in the direction of clockwise and in the opposite direction.

It is possible to send the modeled profile and the surface in the form of table to profilmeter to calculate the parameters of surface roughness and generated surfaces waviness $[8,9,10,11]$.

\section{ROUGHNESS PARAMETERS EVALUATION INDICATORS FOR DESCRIPTION OF GEOMETRIC MODELS PROFILE}

To assess the suitability of individual roughness parameters to describe some geometric features of surface topography two indicators were used.

The first is the correlation coefficient $\rho$ of the relationship between the two sets of data scaled independently of the units of measurement. It measures the strength of a linear relationship.

The properties of the correlation coefficient $\rho$ :

- is an absolute number;

- is in the range of $\langle-1,1>$;

- if $\rho>0$, then for larger values of one feature corresponds (average) greater values of the second characteristic (dependence growing, behave as properties);

- if $\rho<0$, then for values of one feature of the corresponds(average) smaller values of the second feature and vice versa (decreasing relationship, features behave contrary);

- when $\rho=0$, regardless of the values assumed by one of the features, the average value of the other features are the same - they are uncorrelated; 
- correlation coefficient is a measure of the linear relationship between features. When $|\rho|$ is closer to 1, the more "linear" is the relationship between features. [2, 8, 12, 13]

However, one should not draw conclusions based on the value of the correlation coefficient only. Therefore, trying to determine which of the roughness parameters describes best the change in the characteristic profile also included evaluation index takes into account the comparison of percentage changes in the value of the test, modeled profile feature witch change rates roughness parameters. The following formula describes the dependence:

$$
t=\frac{R_{\max }-R_{\min }}{R_{\text {average }}} \cdot 100 \%
$$

where: $R_{\max }$ - maximum value of the examined roughness parameter

$R_{\text {min }}$ - the minimum value of the examined roughness parameter

$R_{\text {average }}$ - the average value of the examined roughness parameters

Qualifying the roughness parameter, as one that could be useful to describe the specific char- acteristics of the roughness model taken into account if the correlation coefficient $\rho$ between the levels of the characteristic model, and the corresponding parameters evaluated roughness is close to one and at the same time the increase in the value of the parameter $t$ is greater than $30 \%$ $[2,8,14]$.

\section{STAGES OF MODELING HONED SURFACE}

To show the stages of modeling surface finish after honing model was used, in which: step along the $\mathrm{x}$-axis is $0,1 \mathrm{~mm}$, disruption at $3 \%$, and the characteristic grain size is $579 \mu \mathrm{m}$, which is $550 \mu \mathrm{m}$ and $29 \mu \mathrm{m}$ respectively for rough honing and for the finish honing.

For creation of the final honed surface carrying several steps is necessary:

1. Modelling of the surface by using abrasive grains for coarse honing with rotation angle $20^{\circ}$.

2. Modelling of the surface by using abrasive grains for coarse honing treatment with rotation angle $-20^{\circ}$.

3. The combination of an area of 1) and 2) using the "folding" function, to give the surface after coarse honing.
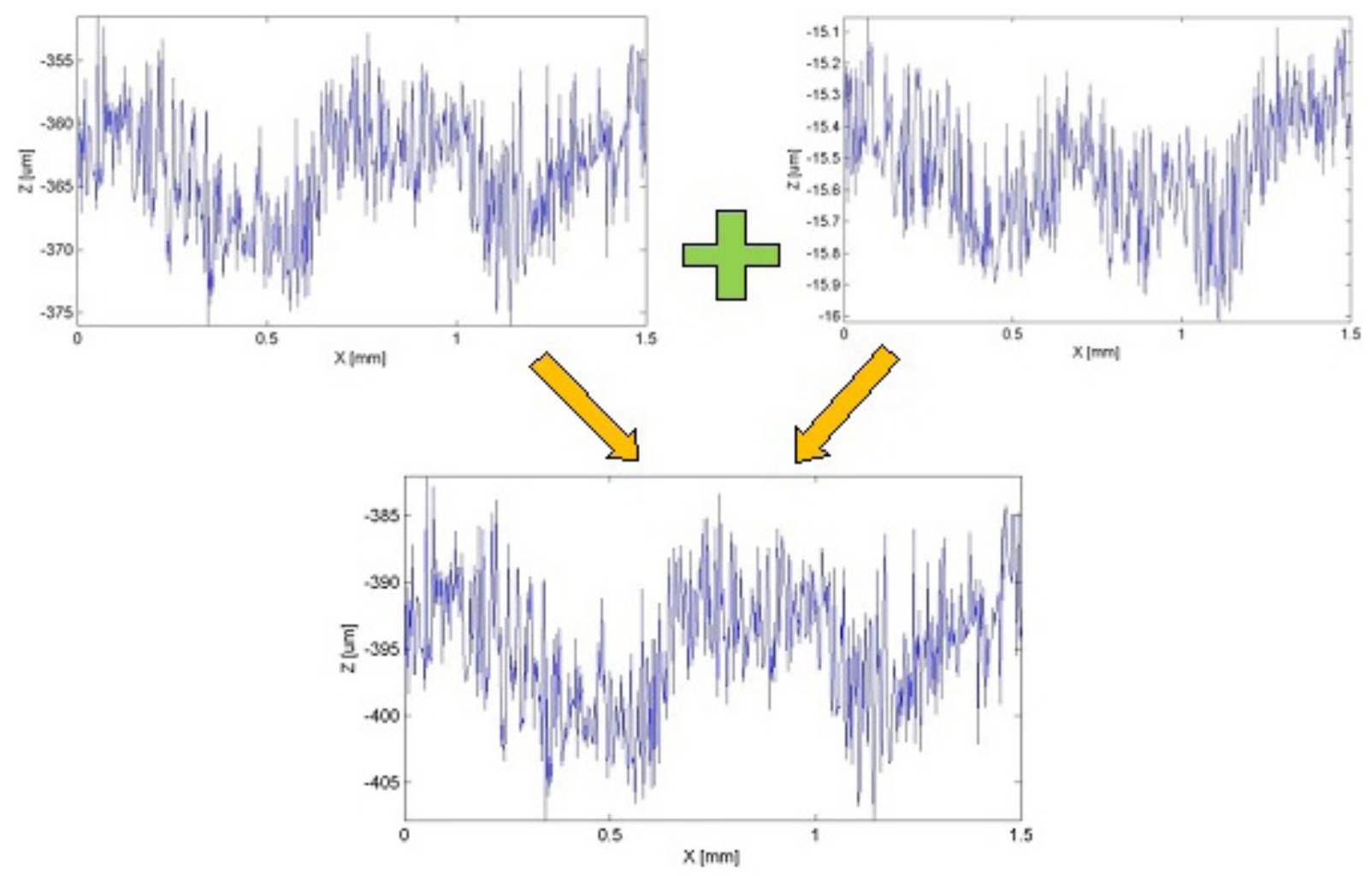

Fig. 2. Structure of the "plateau" as a result of the overlap on itself scratches, resulted in a two-step honing $2 \mathrm{D}$ profile 
4. Modelling of the surface by using abrasive grain for finishing honing treatment with rotation angle $20^{\circ}$.

5. Modelling of the surface using an abrasive grain for finishing honing treatment with $-20^{\circ}$ angle of rotation.

6. The combination of 4) and 5) using the "folding" function, to give surface after finishing honing.

7. The combination of surface 3) and 6) using the "folding" function to get the final surface after dual-procedure honing (Fig. 2).

\section{SAMPLE TEST RESULTS}

\section{Variable grain size}

For research surfaces with the changeable size of the abrasive grain were chosen. In soft- ware changeable size of elementar shape in the $\mathrm{x}$ axis and in the $\mathrm{z}$ axis are on 5 levels which are shown in sequential columns of Table 1 . The profile was shaped by moving, with the set step 0,1 $\mathrm{mm}$, basic shape in the form of the ellipse. Disrupting are on $3 \%$ level.

Calculated 2D roughness parameters and indicators for assessing these parameters are given in Table 2.

The correlation coefficient calculated for the amplitude parameters tells us that the roughness parameters of this group are mostly correlated with the size of the abrasive grain. After analysis of factor $t$ we confirm in above statement, because it is high practically in all parameters. The exception is the slope profile parameter $R k u$, which correlation coefficient is 0,2 and the ratio $t$ only $15 \%$. Changes depending can best be seen in Figure $3 \mathrm{a}$. For parameter $R k u$ change of the abrasive

Table 1. The abrasive grain size in the $\mathrm{x}$-axis and z-axis

\begin{tabular}{|c|c|c|c|c|c|c|}
\hline \multirow{4}{*}{ Rough honing } & Characteristic dimension $[\mu \mathrm{m}]$ & 2200 & 1100 & 550 & 280 & 130 \\
\cline { 2 - 7 } & $\mathrm{x}$ axis $[\mathrm{mm}]$ & 0,7 & 0,4 & 0,2 & 0,09 & 0,04 \\
\cline { 2 - 7 } & $\mathrm{z}$ axis $[\mu \mathrm{m}]$ & 1500 & 700 & 350 & 190 & 90 \\
\hline \multirow{3}{*}{ Finish honing } & Characteristic dimension $[\mu \mathrm{m}]$ & 53 & 45 & 29 & 17 & 13 \\
\cline { 2 - 7 } & $\mathrm{x}$ axis $[\mathrm{mm}]$ & 0,018 & 0,015 & 0,01 & 0,006 & 0,004 \\
\cline { 2 - 7 } & $\mathrm{z}$ axis $[\mu \mathrm{m}]$ & 35 & 30 & 19 & 11 & 9 \\
\hline
\end{tabular}

Table 2. Effect of abrasive grains size on roughness parameters $2 \mathrm{D}$

\begin{tabular}{|c|c|c|c|c|c|c|c|c|}
\hline \multirow{2}{*}{\multicolumn{2}{|c|}{ Parameters }} & \multicolumn{5}{|c|}{ Level of changes of abrasive grain size } & \multirow{2}{*}{$\mathbf{t}[\%]$} & \multirow{2}{*}{$\rho$} \\
\hline & & 2253 & 1145 & 579 & 297 & 143 & & \\
\hline \multicolumn{9}{|c|}{ Roughness parameters 2D } \\
\hline \multicolumn{9}{|c|}{ Amplitude parameters } \\
\hline $\mathrm{Ra}$ & {$[\mu \mathrm{m}]$} & 0,8103 & 0,3958 & 0,2659 & 0,2196 & 0,1082 & 195 & 0,9918 \\
\hline$R q$ & {$[\mu \mathrm{m}]$} & 0,9888 & 0,4997 & 0,3314 & 0,2736 & 0,1348 & 192 & 0,9931 \\
\hline$R p$ & {$[\mu \mathrm{m}]$} & 2,7692 & 1,561 & 0,9612 & 0,7403 & 0,3646 & 188 & 0,9969 \\
\hline$R v$ & {$[\mu \mathrm{m}]$} & 2,4767 & 1,272 & 0,9374 & 0,7269 & 0,358 & 184 & 0,9909 \\
\hline Rt & {$[\mu \mathrm{m}]$} & 5,2459 & 2,8331 & 1,8986 & 1,4672 & 0,7227 & 186 & 0,9951 \\
\hline Rsk & & 0,2728 & 0,2005 & $-0,0549$ & $-0,092$ & $-0,092$ & 778 & 0,9389 \\
\hline$R k u$ & & 2,6513 & 3,0097 & 2,8089 & 2,592 & 2,5921 & 15 & 0,2026 \\
\hline$R z$ & {$[\mu \mathrm{m}]$} & 5,2459 & 2,8331 & 1,8986 & 1,4672 & 0,7227 & 186 & 0,9951 \\
\hline$R c$ & {$[\mu \mathrm{m}]$} & 3,4015 & 1,7808 & 1,1429 & 0,9025 & 0,4445 & 193 & 0,9957 \\
\hline $\mathrm{Rz}(\mathrm{JIS})$ & {$[\mu \mathrm{m}]$} & 4,8026 & 2,6118 & 1,5979 & 1,3094 & 0,6449 & 190 & 0,9962 \\
\hline \multicolumn{9}{|c|}{ Functional parameters } \\
\hline$R k$ & {$[\mu \mathrm{m}]$} & 1,2103 & 0,5321 & 0,402 & 0,2216 & 0,1092 & 222 & 0,9907 \\
\hline Rpk & {$[\mu \mathrm{m}]$} & 0,5024 & 0,1146 & 0,1128 & 0,0819 & 0,0403 & 271 & 0,9414 \\
\hline$R v k$ & {$[\mu \mathrm{m}]$} & 0,4369 & 0,2059 & 0,1556 & 0,0772 & 0,0381 & 218 & 0,9922 \\
\hline Vo & {$\left[\mathrm{mm}^{3} / \mathrm{cm}^{2}\right]$} & 0,0216 & 0,0102 & 0,0077 & 0,0038 & 0,0019 & 218 & 0,9922 \\
\hline
\end{tabular}


a)

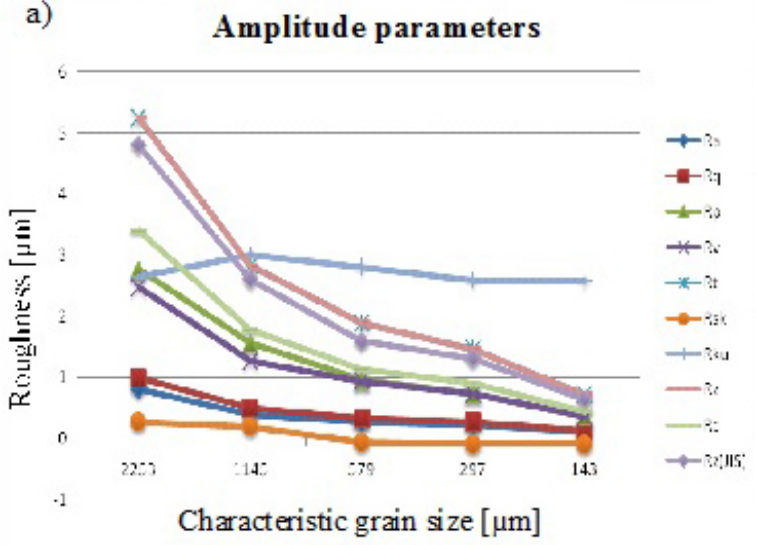

b) Functional parameters part 1

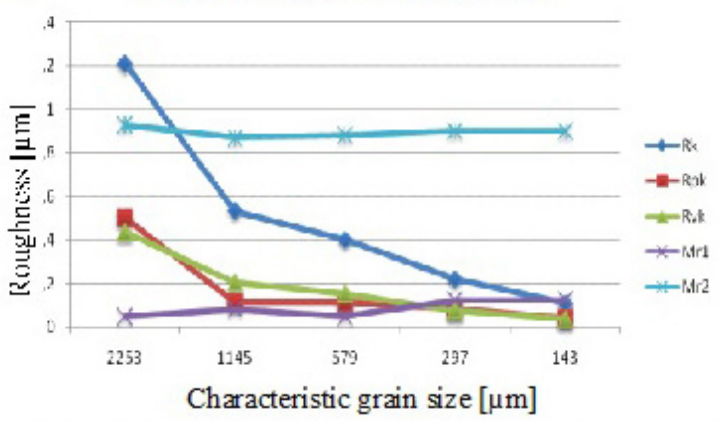

c) Functional param eters part 2

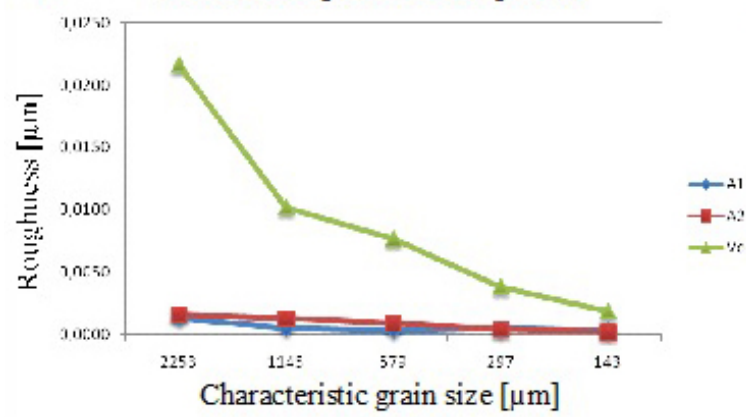

Fig. 3. The dependence of the roughness parameters from variable abrasive grain size

grains size slightly affects on the surface roughness. Line picturing this is nearly parallel to the $\mathrm{x}$-axis and shows minimal variations. Significant changes in the roughness can be see for parameter $R z, R t$ and $R z$ (JIS). With the value of the correlation coefficient and the ratio $t$ also parameters $R c$ and $R p$ are important. The biggest value $t$ was calculated for the asymmetry parameter $R s k$ despite lower correlation coefficient (as compared with other parameters), it was considered appropriate to describe the surface with varying size of the abrasive grain.

In the group of functional parameters the correlation coefficient closest to 1 was calculated for the parameters: $R k, R v k$ and $V o$. On the basis of the indicator parameter $t, R p k$ can also be useful in describing the surface after finish honing. Material shares $(\mathrm{Mr} 1, \mathrm{Mr} 2)$ and surface recesses and valleys $(A 1, A 2)$, does not show practically any changes depending on the changing abrasive grain size. Parameter Vo due to the fact that it is calculated on the basis of $R v k$ becomes important. The dependence of the functional parameters of roughness and the abrasive grain size is shown in Figure $3 b$ and c. Summing up the results of research $2 \mathrm{D}$ roughness it can be concluded that a reduction of the abrasive grain size, which is elementary shape size, decreased all the amplitude parameters. However, there was little correlation coefficient value of skewness Rsk and kurtosis

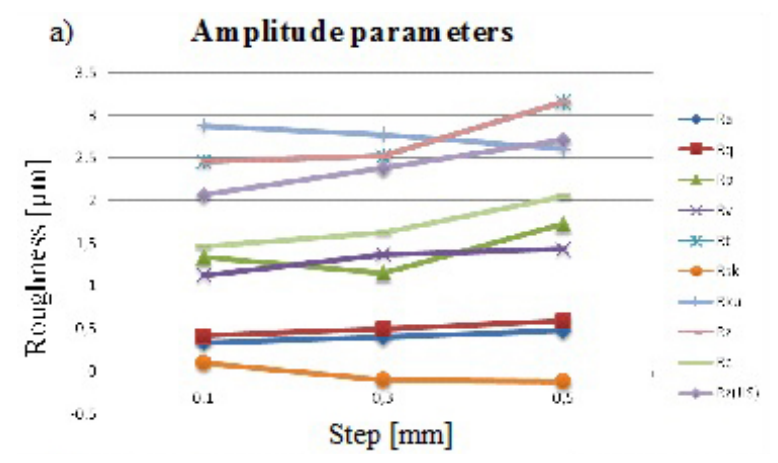

b) Functional par ameters part 1
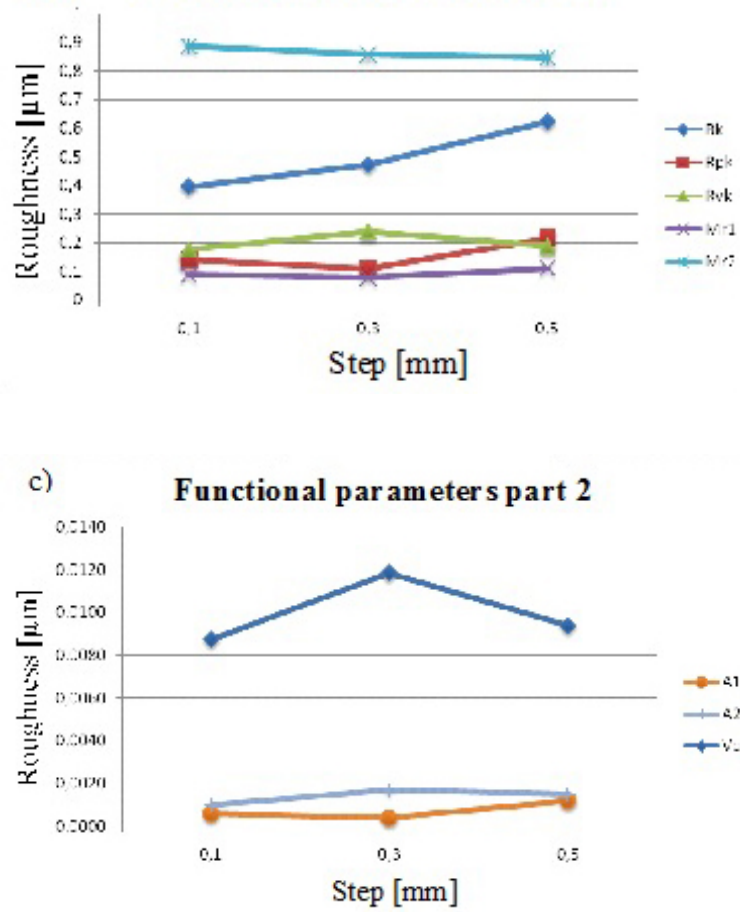

Fig. 4. The dependence of the roughness parameters for the modeled step size (a variable peripheral speed of the tool) 
$R k u$. Changing the size of the abrasive grain can not be described by these parameters.

Group of functional parameters have important parameters to describe the modeled surfaces. High correlation coefficient has a core depth $R k$ and reduced depth of the cavities $R v k$. Due to the fact that it is flat - top surface correlation coefficient for reduced heights peak $R p k$ is slightly lower, although the percentage indicator $t$ is high that is why this was a useful parameter to describe the modeled changes. Vo parameter that is the volume of oil also deserves attention, but please remember that it is calculated on the basis $R v k$. Other roughness parameters, due to the low coefficient of correlation or a small value of $t$ is less useful to the description of the modeled changes in the roughness profile.

\section{Variable peripheral speed}

For researches surfaces with a variable step size of the elementar shape of along the $\mathrm{x}$-axis is selected. This value reflects the variable peripheral speed. The higher the peripheral speed is the lower step is, because traces of processing on the large degree are overlapping each other. Profile was modeled by displacement with a given step elementary shape in a form of an ellipse in axes $x=0,21 \mathrm{~mm}, \mathrm{z}=369 \mu \mathrm{m}$. Step of displacement of elementar shape along the $\mathrm{x}$-axis was adopted at three levels: $0,1 \mathrm{~mm} ; 0,3 \mathrm{~mm} ; 0,5 \mathrm{~mm}$. Interference at $4 \%$ (Table 3 ).

The height of the correlation coefficient calculated for the amplitude parameters can distinguish the following parameters: $R a, R q, R k u$ and $R z$ (JIS). However, after further analysis of factor $t$ of these parameters as important for the description of the changes, $R k u$ parameter is rejected $(t=$ $10 \%)$. The biggest value of $t$ factor was calculated for the parameter $R s k$, however, due to a lower correlation coefficient (as compared with other parameters) could not be considered as significant. In the group of functional parameters correlation coefficient closest to 1 is calculated only for the parameter $R k$. Depth of the core $R k$ becomes useful to describe the changes in the modeled surfaces for the variable shape step size of elementar parameter along the $\mathrm{x}$-axis.

For all other parameters, the correlation coefficient is lower. Percentage changes of indicator $t$ for other parameters are also insignificant. The dependence of the roughness and the step size is shown in Figure 4.

Analyzing the obtained results of $2 \mathrm{D}$ roughness it can be concluded that an increase of the step elementar shape along the $\mathrm{x}$-axis, all parameters increased amplitude parameters. However, not all parameters of the value of the correlation coefficient was close to 1 . It was decided that the

Table 3. Influence of the step size of the elementar shape along the $\mathrm{x}$ axis on roughness parameters $2 \mathrm{D}$

\begin{tabular}{|c|c|c|c|c|c|c|}
\hline \multirow{2}{*}{\multicolumn{2}{|c|}{ Parameters }} & \multicolumn{3}{|c|}{ Level of changes of elementar shape step along $x$ axis } & \multirow{2}{*}{$\mathrm{t}[\%]$} & \multirow{2}{*}{$\rho$} \\
\hline & & 0,1 & 0,3 & 0,5 & & \\
\hline \multicolumn{7}{|c|}{ Roughness parameters 2D } \\
\hline \multicolumn{7}{|c|}{ Amplitude parameters } \\
\hline $\mathrm{Ra}$ & {$[\mu \mathrm{m}]$} & 0,3332 & 0,3955 & 0,4732 & 35 & 0,9980 \\
\hline$R q$ & {$[\mu \mathrm{m}]$} & 0,4176 & 0,4918 & 0,5857 & 34 & 0,9977 \\
\hline$R p$ & {$[\mu \mathrm{m}]$} & 1,3379 & 1,1539 & 1,7264 & 41 & 0,6646 \\
\hline$R v$ & {$[\mu \mathrm{m}]$} & 1,1238 & 1,3691 & 1,4303 & 23 & 0,9448 \\
\hline$R t$ & {$[\mu \mathrm{m}]$} & 2,4617 & 2,523 & 3,1567 & 26 & 0,9031 \\
\hline Rsk & & 0,0981 & $-0,0969$ & $-0,1179$ & -555 & $-0,9067$ \\
\hline Rku & & 2,8796 & 2,7729 & 2,6075 & 10 & $-0,9923$ \\
\hline$R z$ & {$[\mu \mathrm{m}]$} & 2,4617 & 2,523 & 3,1567 & 26 & 0,9031 \\
\hline$R c$ & {$[\mu \mathrm{m}]$} & 1,467 & 1,6252 & 2,0539 & 34 & 0,9664 \\
\hline $\mathrm{Rz}(\mathrm{JIS})$ & {$[\mu \mathrm{m}]$} & 2,0654 & 2,377 & 2,7099 & 27 & 0,9998 \\
\hline \multicolumn{7}{|c|}{ Functional parameters } \\
\hline$R k$ & {$[\mu \mathrm{m}]$} & 0,3964 & 0,4735 & 0,6232 & 46 & 0,9833 \\
\hline Rpk & {$[\mu \mathrm{m}]$} & 0,1421 & 0,1109 & 0,2147 & 67 & 0,6816 \\
\hline$R v k$ & {$[\mu \mathrm{m}]$} & 0,1761 & 0,2389 & 0,1893 & 31 & 0,1993 \\
\hline Vo & {$\left[\mathrm{mm}^{3} / \mathrm{cm}^{2}\right]$} & 0,0087 & 0,0118 & 0,0094 & 31 & 0,2004 \\
\hline
\end{tabular}


modeled changes can be described by the following parameters: $R a, R q$ and $R z(J I S)$. $R k u$ kurtosis, despite the high correlation coefficient, was considered as not significant in the description due to the low percentage change of $t$. In the group of functional parameters high correlation coefficient and significant volume of index $t$ has only a depth of core $R k$. This parameter is therefore useful in describing surface changes. Other roughness parameters, due to the low coefficient of correlation or a small value of $t$ are less useful to the description of the modeled changes in the roughness profile.

\section{CONCLUSIONS}

Mathematical modeling of geometrical characteristics of the surfaces can not fully replace the experimental studies, but in many cases allows for acceleration of parametric evaluation of the surface. Surface models are irreplaceable in cases where the receipt of actual roughness profiles is too expensive or impossible to achieve by modern methods of machining. Article shows that basing on the very simple functions and mathematical operations to model even the most complex surfaces, including the surfaces of topographies similar to those obtained in real conditions.

Computer program presented in work is a mathematical tool that allows for rapid prototyping, basically of any surface. It has a very high potential for shaping the models even very complex topographies with a high degree of similarity to the real surfaces. It can be useful in conducting analytical research and during developing of shaping technologies of surface functional characteristics in industrial environments. Its use should simplify, accelerate and expand the capabilities of assessing the suitability of roughness parameters for describing the specific characteristics of the surface shape.

\section{REFERENCES}

1. Buj-Corral I., Vivancos-Calvet J., Rodero-deLamo L. and Marco-Almagro Ll. Comparison between mathematical models for roughness obtained in test machine and in industrial machine in semifinish honing processes. Procedia Engineering, 132, 2015, 545-552.

2. Cichosz P. and Kowalski M. Modelowanie matematyczne topografii powierzchni płaskowierzchołkowych typu, ,plateau”. XXVII
Naukowa Szkoła Obróbki Ściernej. Koszalin-Sarbinowo. Zeszyty Naukowe Wydziału Mechanicznego, Politechnika Koszalińska, 2004 195-202.

3. Buj-Coral I., Vivancos-Calvet J. and Coba Salcedo M. Use of roughness probability parameters to quantify the material removed in plateau-honing. International Journal of Machine Tools and Manufacture, 50(7), 2010, 621-629.

4. Cabanettes F., Dimkovski Z. and Rosén B.-G. Roughness variations in cylinder liners induced by honing tools' wear. Precision Engineering, 41, 2015, 40-46.

5. Resizer R. and Pawlus P. Modelowanie profile nierówności powierzchni cylindrów po gładzeniu płaskowierzchołkowym. Pomiary Automatyka Robotyka, 6, 2012, 64-69.

6. Pawlus P., Cieslak T. and Mathia T. The study of cylinder liner plateau honing process. Journal of Materials Processing Technology, 209(20), 2009, 6078-6086.

7. Sunnen AG Official Website, (www.sunnen.pl).

8. Cichosz P., Kowalski M. and Kuzinowski M. Matematicko modelirane na topografijata na deterministicki povrsini. Matematyczne modelowanie topografii powierzchni zdeterminowanych. Scientific conference with international participation. Conference proceedings. University "Ss. Cyril and Methodius", Skopje, Republic of Macedonia, 2004, 106-111.

9. Sadílek M., Kratochvíl J., Petrů J., Cep R., Zlámal T. and Stančeková D. Cutting tool wear monitoring with the use of impedance layers. Tehnicki Vjesnik, 21(3), 2014, 639-644.

10. Goeldel B., El Mansori M. and Dumur D. Simulation of roughness and surface texture evolution at macroscopic scale during cylinder honing process. Procedia CIRP, 8, 2013, 27-32.

11. Sivatte-Adroer M., Llanas-Parra X., Buj-Corral I. and Vivancos-Calvet J. Indirect model for roughness in rough honing processes based on artificial neural networks. Precision Engineering, 43(1), 2016, 505-513.

12. Deepak Lawrence K. and Ramamoorthy B. Multisurface topography targeted plateau honing for the processing of cylinder liner surfaces of automotive engines. Applied Surface Science, 365, 2016, $19-30$.

13. Fulemová J. and Řehoř J. Influence of form factor of the cutting edge on tool life during finishing milling. Procedia Engineering. Vídeň, Elsevier, 2015, 682-688.

14. Valášek P., Müller M. and Hloch S. Recycling of corundum particles - two-body abrasive wear of polymeric composites based on waste. Tehnicki Vjesnik-Technical Gazette, 22(3), 2015, 567-572. 